\title{
Ascorbic acid and long-term anticonvulsant therapy in children
}

\author{
BY K. P. DAWSON \\ Paediatric Department, Law Hospital, Carluke, Lanarkshire ML8 5 ER \\ AND ANNE DUNCAN* \\ The Department of Biochemistry, Royal Infirmary, Glasgow \\ (Received I8 February I974 - Accepted 29 October 1974)
}

\footnotetext{
I. Forty-eight children, who were long-term hospital patients, were investigated to assess their leucocyte ascorbic acid status.

2. Twenty-nine children had been receiving long-term anticonvulsant therapy, and these children did not have a significantly lower level of ascorbic acid than the untreated group, which did not have epilepsy.

3. The ascorbic acid levels of all subjects were low and seventeen had levels between $7 \cdot 3$ and $\mathrm{I} 6 \cdot 0 \mu \mathrm{g} / \mathrm{IO}^{8}$ white blood cells.
}

The ever-increasing number of adverse effects described in children given longterm anticonvulsant therapy has prompted us to investigate the effects of the anticonvulsants on ascorbic acid levels in the leucocytes of children.

It is now established that certain drugs such as phenylbutazone and chlorcyclizine stimulate markedly the urinary excretion of ascorbic acid (Conney, Bray, Evans \& Burns, 196r). Therefore a group of children was investigated to determine their ascorbic acid status in relationship to their anticonvulsant intake.

\section{METHODS}

\section{Subjects}

Forty-eight children aged between 5 and $\mathrm{i} 6$ years were investigated. Twenty-nine had been receiving anticonvulsant drugs for a minimum of $\mathbf{I}$ year, with a range of I-IO years. Nineteen children, who acted as controls, were receiving no drug therapy in any form. All subjects were long-term care patients in Bellfield Hospital, Lanark, with mental deficiency, with or without epilepsy. Ascorbic acid estimations were done during the months of August and September. None of the epileptic subjects was receiving any other drug, including tetracyclines. The dietary intake of ascorbic acid, before cooking, was calculated as ranging from 77 to $133 \mathrm{mg} / \mathrm{d}$. Permission was obtained for blood sampling. Ascorbic acid status was assessed by measuring leucocyte ascorbic acid (LAA) levels. All the children involved were examined and no clinical signs of ascorbic acid deficiency were observed.

* For reprints. 
Table 1. Leucocyte ascorbic acid $(L A A)$ levels $\left(\mu g / 10^{8}\right.$ white blood cells) of epileptic children who had been receiving long-term anticonvulsant therapy and untreated children who did not have epilepsy

\begin{tabular}{cccc} 
& & Controls & Epileptics \\
No. of subjects & $\ldots$ & I9 & 29 \\
LAA Mean & & $18 \cdot 95$ & $16 \cdot 80$ \\
SE & & $1 \cdot 09$ & 0.95 \\
CV & $255^{\circ}$ & 30.6 \\
\multicolumn{3}{c}{ CV, coefficient of variation. }
\end{tabular}

\section{LAA method}

LAA was measured by the method of Denson \& Bowers (I96I). The buffy layers, which were prepared by the method recommended by McCraw \& Sim (1969), were centrifuged immediately and the cellular deposits obtained were ground with $\mathrm{I} \cdot 3 \mathrm{ml}$ trichloroacetic acid solution $(5 \circ \mathrm{g} / 1)$. The trichloroacetic acid extracts were stored at $0-4^{\circ}$ for a maximum of $2 \mathrm{~d}$ if the estimation could not be done immediately. Reproducibility of the estimations was tested by using two $3 \mathrm{ml}$ portions from each blood sample. Analysis of the results indicated that duplicate determinations on the same sample gave a mean difference of $\mathrm{I} \cdot 47 \mu \mathrm{g} / \mathrm{IO}^{8}$ white blood cells (WBC) (SD $\mathrm{r} \cdot 6 \mathrm{r}$ ).

\section{RESULTS}

The results are shown in Table $\mathrm{I}$ and Fig. $\mathrm{I}$. There was no statistically significant difference between the two groups.

\section{DISCUSSION}

The ever-increasing number of metabolic effects of anticonvulsants, such as folic acid deficiency and hypocalcaemia, has prompted us to investigate their effects on the ascorbic acid levels of epileptics.

We have assessed ascorbic acid status by measuring the leucocyte levels. It is generally agreed that this is a reliable and convenient index of tissue levels of the individual (Gibson, Moore \& Goldberg, r966). Denson \& Bowers (196r) reported a mean value of $13.7 \mu \mathrm{g} / \mathrm{IO}^{8} \mathrm{WBC}$ in fifty elderly people compared with a mean control value of $35^{\circ} \circ \mu \mathrm{g} / 10^{8} \mathrm{WBC}$ in working adults. Gibson et al. (1966) quote values for normal subjects aged $\mathrm{r} 8-54$ years of $2 \mathrm{I}-57 \mu \mathrm{g} / 10^{8} \mathrm{WBC}$. Using the same biochemical methods as in this investigation, Cohen \& Duncan (1967) found that for fourteen young adults, with a mean age of 22 years, the mean LAA level was $2 \mathrm{I} \cdot 7 \mu \mathrm{g} / \mathrm{IO}^{8} \mathrm{WBC}$. Elderly patients in hospital have been found to have LAA levels below $15 \mu \mathrm{g} / 10^{8} \mathrm{WBC}$ and this has been attributed to ascorbic acid having been largely destroyed in cooking and serving meals (Platt, Eddy \& Pellet, I963).

Tetracyclines have been shown to cause a decrease in ascorbic acid levels (Windsor, Hobbs, Treby \& Astley Cowper, 1972). None of our subjects was receiving antibiotics at the time of the investigation or immediately beforehand. 


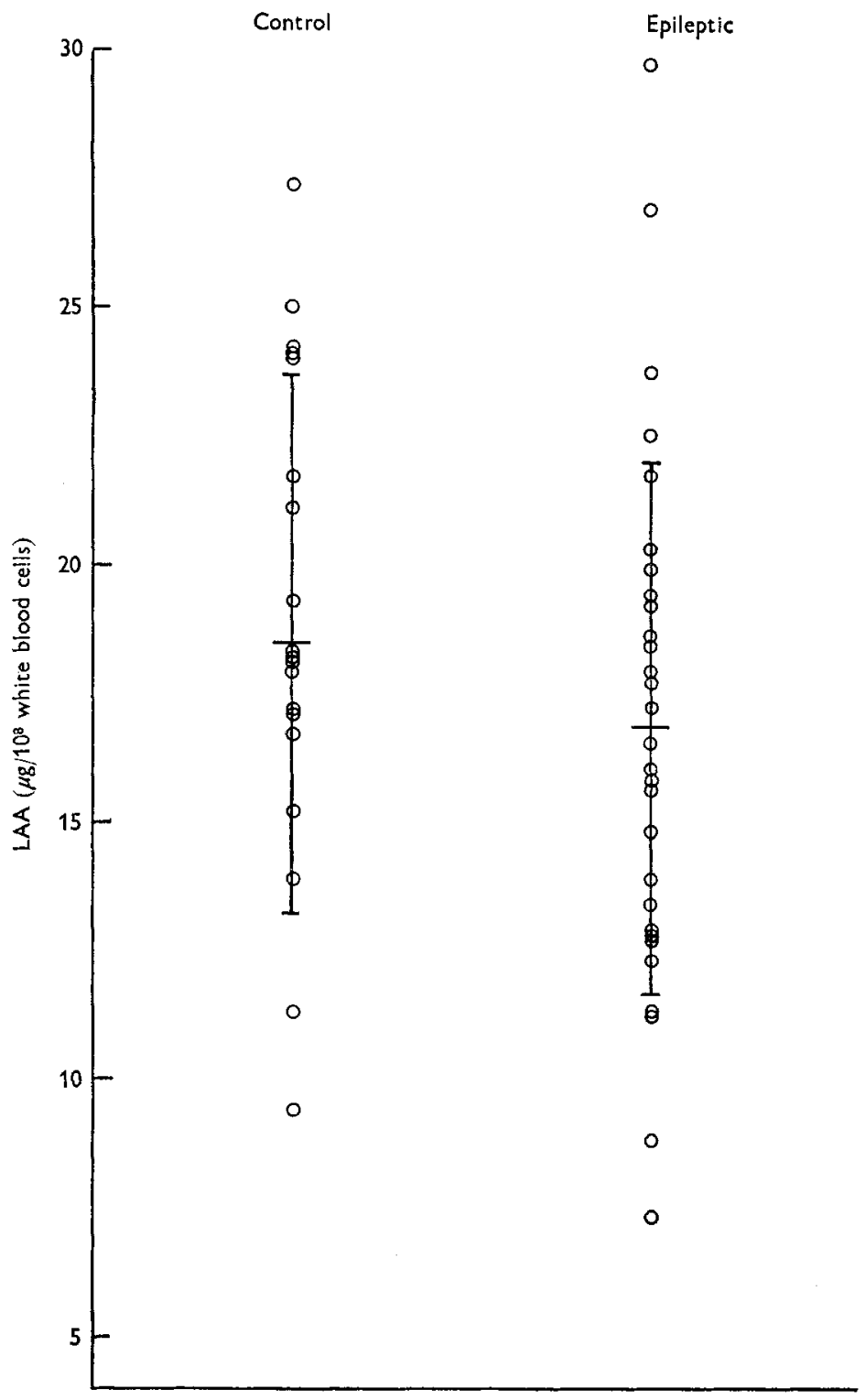

Fig. I. Distribution of leucocyte ascorbic acid (LAA) levels in twenty-nine epileptic children who had been receiving long-term anticonvulsant therapy and nineteen untreated children who did not have epilepsy. Mean values and standard deviations represented by vertical bars.

Wewere impressed by the fact that seventeen of the subjects had LAA levels between $7 \cdot 3$ and $\mathrm{I} 6 \cdot \circ \mu \mathrm{g} / \mathrm{ro}^{8} \mathrm{WBC}$. Three subjects had LAA levels below $\mathrm{I} \circ \mu \mathrm{g} / \mathrm{ro}^{8} \mathrm{WBC}$, which must be regarded as extremely low when compared with all published values. In all subjects with low LAA levels and particularly those with levels below ro $\mu \mathrm{g} / \mathrm{ro}^{8} \mathrm{WBC}$ we could not find any infection or other reason for considering them separately from the other subjects. The calculated intake of ascorbic acid appeared to be adequate for the group and we can only presume that the effects described by Platt et al. ( $\left(\mathrm{g}^{6}{ }_{3}\right)$ must 
be applicable for a population of mentally-retarded children. LAA levels are known to be significantly higher between July and December (Milne, Lonergan, Williamson, Moore, McMaster \& Percy, 1971). Our subjects were studied in the months of August and September and LAA levels were, therefore, probably at their peak values.

One subject was excluded because he was receiving ascorbic acid supplements and had a LAA level of $43.3 \mu \mathrm{g} / \mathrm{ro}^{8} \mathrm{WBC}$, confirming the effect of supplementation.

Kimball (1939) was the first to suggest that ascorbic acid deficiency was the cause of severe gingival hypertrophy in patients treated with phenytoin. Milton \& Osterberg (1942) could not demonstrate a deficiency in blood and urine and this association was thereafter discounted. However, Collins, Morgan \& Corum (194I) treated five epileptics with varying doses of ascorbic acid claiming that there was an increased frequency of seizures.

Ascorbic acid is involved in cell function, enzyme action and protein metabolism. Sim (1972) discussed the action of ascorbic acid in terms of its reducing activity, contributing to biochemical reactions, the regeneration of tissue, collagen formation and bone deposition, the conversion of folic acid to $5-\mathrm{N}$-formyltetrahydrofolic acid, and involvement in the maintenance of blood lipid levels. In view of the many actions of ascorbic acid, particularly in relation to folic acid, it would be important to exclude the action of anticonvulsants on the ascorbic acid status of epileptics. The results of this study, however, give no indication that children given long-term anticonvulsant therapy had lower LAA levels than control subjects.

This study, however, emphasizes that long-term hospital patients of any age with low LAA levels probably require supplementation with ascorbic acid if institutional cooking and food presentation have been found to be satisfactory.

The authors wish to thank Dr G. A. MacDonald and staff of the Haematology Department, Royal Infirmary, Glasgow, who did the white blood cell counts.

\section{REFERENCES}

Cohen, M. M. \& Duncan, A. M. (1967). Br. med. F. iv, 516.

Collins, J. G., Morgan, J. D. \& Corum, C. L. (1941). Med. Bull. Veterans' Adm. 18, 30r.

Conney, A. H., Bray, G. A., Evans, C. \& Burns, J. J. (1961). Ann. N.Y. Acad. Sci. 92, Ir 5.

Denson, K. W. \& Bowers, E. F. (196r). Clin. Sci. 21, I57.

Gibson, S. L. M., Moore, F. M. L. \& Goldberg, A. (1966). Br. med. F. i, I 52.

Kimball, O. P. (1939). F. Am. med. Ass. 1r2, 244.

McCraw, A. \& Sim, A. K. (1969). Clinica chim. Acta 25, 286.

Milne, J. S., Lonergan, M. E., Williamson, J., Moore, F. M. L., McMaster, R. \& Percy, N. (I97I). Br. med. $\mathcal{Y}$. iv, 383 .

Milton, J. A. \& Osterberg, A. E. (1942). F. Am. dent. Ass. 29, 207.

Platt, B. S., Eddy, T. P. \& Pellet, P. L. (1963). Food in Hospitals p. 69. London: Oxford University Press.

Sim, A. K. (1972). Chemy Ind. no. 4, p. 160.

Windsor, A. C. M., Hobbs, C. B., Treby, D. A. \& Astley Cowper, R. (1972). Br. med. F. i, 214 . 